\title{
Lipid and exopolysaccharide production during hydrocarbon growth of a marine bacterium from the sea surface
}

\author{
Madeleine Goutx, Stéphanie Mutaftshiev, Jean-Claude Bertrand \\ ' Centre d'Océanologie de Marseille, URA 41, Faculté des Sciences de Luminy, F-13288 Marseille Cedex 9, France \\ ${ }^{2}$ Laboratoire de Chimie et de Biochimie Moléculaire, Centre National de la Recherche Scientifique, Chemin Joseph Aiguiers, \\ 13009 Marseille, France
}

\begin{abstract}
The marine bacterium Alcaligenes sp. PHY 9 L.86 was isolated from hydrocarbon-polluted sea-surface waters and grown on $0.1 \%$ tetradecan in batch cultures. Lipid composition of cell pellets and supernatants were examined throughout growth, using thin layer chromatography coupled with flame ionization detection. Cellular and extracellular carbohydrate and protein contents were estimated. Bacterial growth on hydrocarbon induced the production of extracellular emulsifying agents (biosurfactants). Formation of foams was observed in the culture medium at early stationary phase; it was related to high emulsifying activity and maximum extracellular lipid production (in particular, free fatty acids and triglycerides). Specific staining for acid polysaccharides revealed the formation of exopolysaccharid fibers associated with vesicles, the size of which depended on the growth phase. Surface-active agents produced by Strain. PHY 9 L. 86 explain the foam formation. Our results stress the role of biosurfactants in the biodegradation of hydrocarbon in the marine environment.
\end{abstract}

\section{INTRODUCTION}

In coastal areas of the Gulf of Marseille (France), which is chronically polluted with hydrocarbons, foams can frequently be observed at the sea surface. The ability of these foams to emulsify crude oil was noted by Rambeloarisoa et al. (1984). Emulsifying agents are responsible for foam formation. They can be either synthetic emulsifiers (detergents) or tensioactive molecules of biological origin (biosurfactants). The fact that detergents have not been detected suggests a biological origin of the foams.

Studies by Rambeloarisoa et al. (1984) showed that hydrocarbons and hydrocarbonoclastic bacteria accumulated extensively in these foams $\left(10^{7}\right.$ to $10^{8}$ bacteria $\mathrm{ml}^{-1}$ ). The ability of bacteria growing on hydrocarbon substrates to produce emulsifying agents is well known (Rosenberg 1986). Thus, the production of surface-active molecules by bacteria could be an important factor involved in foam formation. A mixed bacterial community (EM4) composed of 8 bacterial strains which degraded crude oil very effectively was isolated from foams (Rambeloarisoa et al. 1984). Among this community, the marine Strain PHY 9 L.86 exhibited a maximum efficiency for degrading hydro- carbon substrate; it was therefore selected for detailed investigation of the production of emulsifying agents.

In this study, a qualitative and quantitative analysis of compounds released into the culture medium by Strain PHY 9 L.86 was performed at various phases of the bacterial culture grown on hydrocarbon substrate.

\section{MATERIAL AND METHODS}

Organisms and growth conditions. The bacterial Strain PHY 9 L.86 was identified as Alcaligenes sp. according to the classification system proposed by Buchanan \& Gibbons (1974).

Bacteria were grown at $30^{\circ} \mathrm{C}$ in 21 Fernback flasks containing $300 \mathrm{ml}$ of mineral salt medium with the following composition (in $\mathrm{g} \mathrm{l}^{-1}$ distilled water): Tris (hydroxymethyl amino methane) (6.05), $\mathrm{NaCl}(23), \mathrm{KCl}$ (0.75), $\mathrm{CaCl}_{2}$ (1.47), $\mathrm{NH}_{4} \mathrm{Cl}$ (3.74), $\mathrm{MgSO}_{4} .7 \mathrm{H}_{2} \mathrm{O}$ (12.3), $\mathrm{NaHPO}_{4}(0.4 \mathrm{mM})$. The $\mathrm{pH}$ was adjusted to 7.8 with Titrosol (Merck) (4 N).

Tetradecane $(0.1 \%, v / v)$ was provided as sole carbon and energy source. Aeration was provided by agitation on a reciprocal shaker ( $96 \mathrm{rpm}$ ). Growth was monitored by following absorbance at $450 \mathrm{~nm}$ with a Shimadzu 
UV-visible spectrophotometer, by viable count estimates on agar medium plates (filtered seawater enriched with $15 \mathrm{~g} \mathrm{l}^{-1}$ Bio-Trypcase [Merieux], $5 \mathrm{~g} \mathrm{l}^{-1}$ Phytone [Merieux], $15 \mathrm{~g} \mathrm{I}^{-1}$ Agar [Difco]) or by estimating the protein content using the method of Lowry et al. (1951).

Whole contents of the flasks were harvested at various phases of growth, either for electron microscopical studies or chemical analyses.

Emulsifying activity of the $6000 \times \mathrm{g}$ supernatant was measured as a function of the degree of stability of an emulsion obtained after 5 min mechanical agitation of a reaction system or after exposure to sonic oscillation (Zosim et al. 1982) with 2 impulses for 1 min at $9 \mathrm{kHz}$ each. The reaction system contained a determined quantity of supernatant corresponding to an amount of $0.09 \mathrm{mg}$ total sugars (estimated accorcing to the method of Dubois et al. 1956) (the quantity of liquid used could vary between cuiture media, but the sugar concentration remained constant), and $0.1 \mathrm{ml}$ of tetradecane and mineral salt medium without $\mathrm{NH}_{4} \mathrm{Cl}$ to a final volume of $10 \mathrm{ml}$. The stability of the emulsion over time was measured at $610 \mathrm{~nm}$ (Roy et al. 1979) at $20^{\circ} \mathrm{C}$. A similar reaction system prepared from synthetic seawater (i.e. without biosurfactants) served as control.

Electron microscopy. Aliquots of cultures were sampled under the tetradecane upper layer and prepared for electron microscopy analysis. The techniques used were adapted to allow for the high fragility of the surface materials (exopolysaccharides, vesicules, etc). Since the classical methods of preparation for electron microscopic observation of thin sections turned out to be inappropriate, we used either negative staining with $1 \%$ potassium phosphotungstate (PTA) and $1 \%$ uranyl acetate (UA), with or without previous stabilization of the bacterial surface structures with ruthenium red/ glutaraldehyde (G/RR/UA) which specifically reveals acidic polysaccharides (Mutaftshiev et al. 1982). A carbon-coated Formvar grid was deposited on top of a drop of a bacterial cell suspension culture, and left (2 min) for adsorption of the bacteria and their exostructures on the carbon surface. Free-standing material was removed by blotting with filter paper. Grids were treated with a mixture (v/v) of $1 \%$ glutaraldehyde and $1 \%$ ruthenium red, and then contrasted with $0.1 \%$ uranyl acetate. Grids were stained for $5 \mathrm{~min}$ and examined with a Hitachi 600 electron microscope at $75 \mathrm{kV}$

Analytical methods. Centrifugation (6000 $\times \mathrm{g}$ for 15 min, twice, at $5^{\circ} \mathrm{C}$ ) of cultures yielded 2 fractions designated cell pellets and supernatant. The 2 freeze-dried fractions were analysed for protein, carbohydrate and lipid content. Protein was estimated according to the method of Lowry' et al. (1951) with bovine serum albumin as standard. Carbohydrate was estimated using the phenol-sulfuric acid method of Dubois et al. (1956). Lipid was extracted according to the method of Bligh \& Dyer (1959). Aliquots of the lyophilized fractions were suspended in 0.8 volumes of distilled water, 1 volume of chloroform and 2 volumes of methanol. The mixture was stirred overnight under nitrogen. After addition of 1 volume chloroform and 1 volume distilled water and stirring for $10 \mathrm{~min}$, the mixture was filtered through $\mathrm{GF} / \mathrm{C}$ glass fiber filters. Filtrates were allowed to separate into 2 phases. The bottom phase was collected as the lipid extract. The filter was again extracted using the same procedure and the extracts combined.

Lipids were separated by thin-layer chromatography coupled with flame ionization detection (TLC/FID) using a Iatroscan apparatus $\mathrm{TH} 10$ (Iatron Laboratories. Tokyo). The Iatroscan was operated with a hydrogen flow of $75 \mathrm{~kg} \mathrm{~cm}^{-2}$, an air flow of $2000 \mathrm{ml} \mathrm{min}^{-1}$ and a scanning speed of $0.32 \mathrm{~cm} \mathrm{~s}^{-1}$ (30 tooth gear). The Iatroscan was connected to a Shimadzu-chromatopac CR1B Integrator. Lipid classes were separated on chromarods S II using several developments and partial scans, as proposed by Parrish \& Ackman (1983). In the first development $(40 \mathrm{~min}$ hexane-diethyl etherformic acid 99:1:0.1), the less polar lipids (hydrocarbons [HC], wax esters [WE] and free fatty acids [FFA]) moved away from the point of application. There were scanned and the scan was stopped manually. The remaining neutral lipids (triacyglycerides [TG]; fatty alcohols [Alc]; diacylglycerides [DG]; sterols [ST]) were separated in the second development $(40$ min in hexane-diethyl ether-formic acid $80: 20: 0.1$ ). Again, a partial scan was performed. This was followed by a short development in acetone $(3 \mathrm{~cm}$ above the origin). This development separates monoglycerides, glycolipids and pigments from total phospholipids which do not move in acetone. In this set of samples, the pigments were visibly separated from monoglycerides and glycolipides. Lipids were identified on the basis of their ability to co-chromatograph with authentic standards purchased from Sigma LTP Corp. Lipids were quantified with reference to calibration curves performed for each rod and each class of compound. Each rod was considered as an isolated analytical unit as recommended by Delmas et al. (1984). Calibrations were performed at 5 levels with loads in the range 0.5 to $20 \mu \mathrm{g}$.

\section{RESULTS}

\section{Bacterial growth and emulsifying activity}

No growth of Strain PHY 9 L.86 was obtained at sodium chloride concentrations between 0 and $100 \mathrm{mM}$. Maximum growth was achieved at a sodium 
chloride concentration of $400 \mathrm{mM}$; Alcaligenes sp. PHY 9 is thus a marine bacterium according to the definition of Larsen (1986). Typical growth curves are given in Fig. 1 Cultures were harvested at $\log$ phases $\left(T_{1}, T_{2}\right)$,

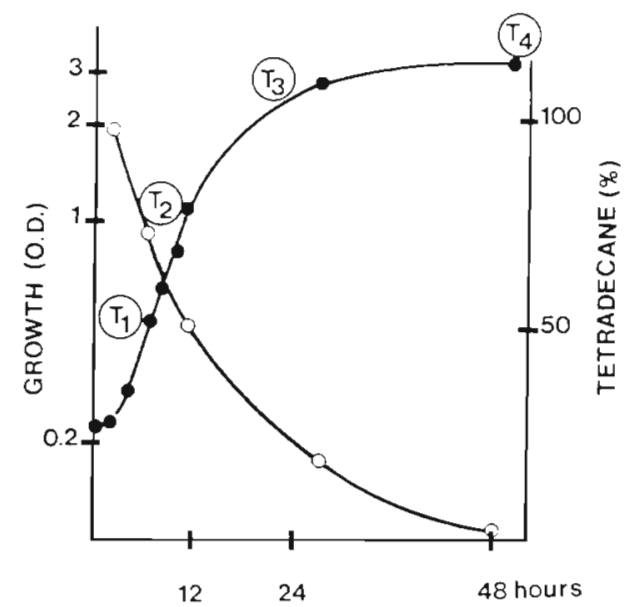

Fig. 1 Alcaligenes sp. PHY $9 \mathrm{~L} .86$ growth and tetradecane consumption. $\mathrm{T}_{1}=7 \mathrm{~h}_{i} \mathrm{~T}_{2}=12 \mathrm{~h}_{i} \mathrm{~T}_{3}=27 \mathrm{~h}_{;} \mathrm{T}_{4}=50 \mathrm{~h}$

early stationary phase $\left(\mathrm{T}_{3}\right)$, stationary phase $\left(\mathrm{T}_{4}\right)$ and after $7 \mathrm{~d}$ growth $\left(\mathrm{T}_{5}\right)$. Protein contents of the whole cultures were 20.66, 55.36, 156.45, 230.61 and $158.62 \mathrm{mg} \mathrm{l}^{-1}$ respectively. Generation time was 240 min, and a value of $1 \times 10^{-6} \mu \mathrm{g}$ protein $\mathrm{cell}^{-1}$ was obtained by measuring protein-to-cell ratios during exponential growth. A maximum of $9 \times 10^{9}$ cells $\mathrm{ml}^{-1}$ was obtained. Tetradecane $(98 \%)$ was degraded within $48 \mathrm{~h}$ (Fig. 2). At $\mathrm{T}_{1}$, the hydrocarbon substrate partitioned between cell pellets (54.3\%) and supernatant $(45.6 \%)$. Afterwards the ratio of tetradecane in supernatant/tetradecane associated with cell pellets increased while total tetradecane concentration decreased. By estimating the protein yield resulting from the microbial oxidation of $1 \%$ tetradecane sub-

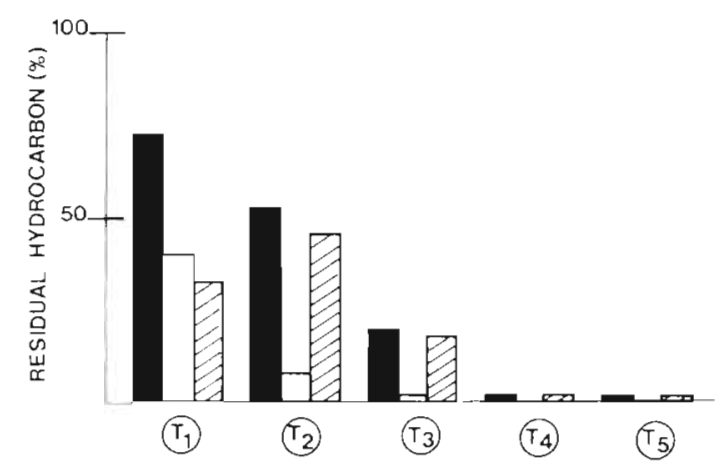

Fig. 2. Alcaligenes sp. PHY 9 L.86. Substrate partitioning between cells and supernatant during growth. Black columns: total substrate; open columns: substrate in cell pellets; hatched columns: substrate in supernatant strate, the optimum rate of cell yield was achieved between $T_{3}$ and $T_{4}$. Foaming appeared at $T_{3}$ and remained stable in cultures until the end of the stationary phase.

The ability of extracellular compounds produced by Strain PHY 9 L.86 to emulsify tetradecane was studied at various phases of the bacterial culture. Optical density of the emulsion in the reaction system and its stability over time were low at the beginning of the exponential growth phase $\left(T_{1}\right)$, enhanced by mid-exponential growth $\left(\mathrm{T}_{2}\right)$ and reached a maximum in the early stationary phase $\left(\mathrm{T}_{3}\right)$. At this time, the optical density (O.D.) of the emulsion in the reaction system was 0.98 ; it remained stable at $80 \%$ of the initial O.D. after $3 \mathrm{~h}$ incubation (Fig. 3 ).

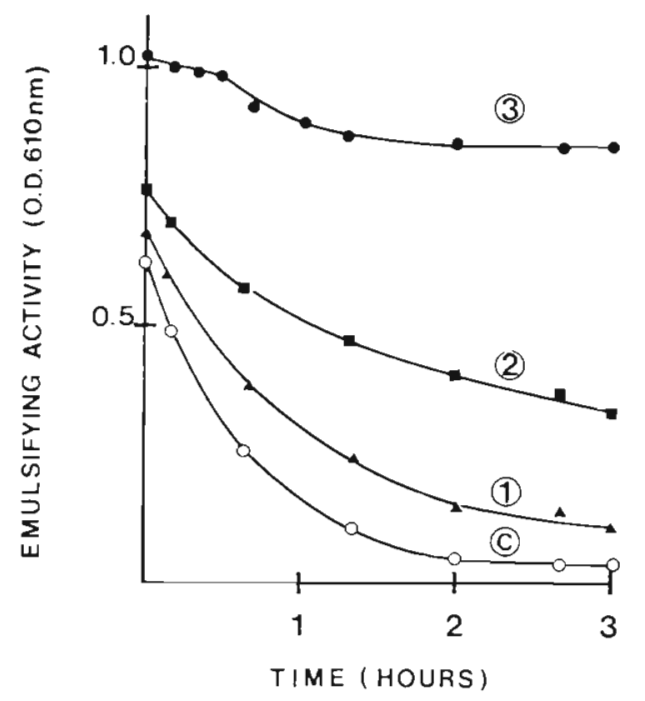

Fig. 3. Alcaligenes sp. PHY 9 L.86. Emulsifying activity at different phases of culture growth. $C$ : control; $1: T_{1}=7 \mathrm{~h} ; 2: \mathrm{T}_{2}$ $=12 \mathrm{~h}_{i}: \mathrm{T}_{3}=27 \mathrm{~h}$

\section{Cellular and extracellular protein, total lipid and carbohydrate contents}

Comparative values of total protein, lipid and carbohydrate contents of cell pellets and extracellular culture broth are listed in Table 1 . The amount of carbohydrates in cell pellets remained relatively constant during growth and averaged $0.48 \mathrm{mg} \mathrm{mg}^{-1}$ protein. Cellular lipid content gradually decreased from 0.138 to $0.030 \mathrm{mg} \mathrm{mg}^{-1}$ protein. In contrast, large increases in extracellular lipids and carbohydrates were apparent, in the early stationary phase for lipids and in the stationary phase for carbohydrates. Maximum values were $7.91 \mathrm{mg} \mathrm{l}^{-1}$ for lipids and $12.63 \mathrm{mg}$ $\mathrm{l}^{-1}$ for carbohydrates. Low amounts of protein were found in the culture supernatant. The maximum value 
Table 1 Alcaligenes sp. PHY 9 L.86. Protein, carbohydrate (CHO) and lipid contents in cells and supernatant from tetradecanegrown cultures

\begin{tabular}{|c|c|c|c|c|c|c|c|}
\hline \multirow[t]{2}{*}{ Culture phase } & & \multicolumn{3}{|c|}{ Cells } & \multicolumn{3}{|c|}{ Supernatant } \\
\hline & & $\mathrm{mg}$ protein $\mathrm{l}^{-1}$ & $\begin{array}{c}\mathrm{mg} \mathrm{CHO} \\
\mathrm{mg}^{-1} \text { protein }\end{array}$ & $\begin{array}{c}\text { mg lipid } \\
\mathrm{mg}^{-1} \text { protein }\end{array}$ & mg protein & $\underset{1^{-1}}{\mathrm{mg} \mathrm{CHO}}$ & $\underset{1^{-1}}{m g ~ l i p i d}$ \\
\hline Log phase 1 & $T_{i}$ & 20.66 & 0.49 & 0.104 & 1.79 & 4.10 & 2.32 \\
\hline Log phase 2 & $\mathrm{~T}_{2}$ & 55.36 & 0.74 & 0.138 & 2.30 & 5.18 & 3.44 \\
\hline Early stationary & & & & & & & \\
\hline phase & $\mathrm{T}_{3}$ & 156.45 & 0.40 & 0.043 & 3.46 & 5.36 & 7.91 \\
\hline Stationary & & & & & & & \\
\hline $\begin{array}{l}\text { phase } \\
7 \mathrm{~d}\end{array}$ & $\begin{array}{l}\mathrm{I}_{4} \\
\mathrm{~T}_{5}\end{array}$ & $\begin{array}{l}230.61 \\
158.62\end{array}$ & $\begin{array}{l}0.44 \\
0.36\end{array}$ & $\begin{array}{l}0.032 \\
0.030\end{array}$ & $\begin{array}{l}4.30 \\
5.07\end{array}$ & $\begin{array}{l}12.63 \\
11.72\end{array}$ & $\begin{array}{l}3.34 \\
2.47\end{array}$ \\
\hline
\end{tabular}

Table 2. Alcaligenes sp. PHY 9 L.86. Quantitation of cellular lipids ( $\mathrm{gg} \mathrm{mg}^{-1}$ protein) at various phases of bacterial growth

\begin{tabular}{|lcccccccc|}
\hline Lipid class & $\mathrm{T}_{1}$ & \% lipid & $\mathrm{T}_{2}$ & \% lipid & $\mathrm{T}_{3}$ & \% lipid & $\mathrm{T}_{4}$ & \% lipid \\
\hline Phospholipids & 120.0 & 86.5 & 104.0 & 96.7 & 43.0 & 95.6 & 32.0 & 99.8 \\
Monoglycerides & 2.7 & 1.9 & 0.16 & 0.001 & 0.05 & 0.11 & 0.05 & 0.2 \\
Diglycerides & Trace & - & Trace & - & - & - & - & - \\
Wax esters & 16.0 & 11.5 & 3.40 & 3.16 & 1.90 & 4.22 & - & - \\
\hline
\end{tabular}

was observed during stationary phase; it ranged up to $2.6 \%$ of the culture protein content before centrifugation. This observation indicates that cell biomass was not concentrated in the supernatant and that lipids and carbohydrates were extracellular compounds.

\section{Lipid analysis}

Data for the main cellular and extracellular lipid classes, isolated via thin layer chromatography on chromarods, are given in Tables 2 and 3 . Comparative analyses were performed on some samples using the TLC/FID technique and classical thin layer chromatography to ascertain the nature of the lipid class in samples.

Phospholipids were major components of cellular lipids. Their relative concentration averaged $94.6 \%$ of total lipids and increased during growth of Alcaligenes sp. PHY 9. Neutral lipids represented 4 to $13 \%$ of total lipids and were mainly composed of wax esters and monoglycerides. Free fatty acids and triglycerides were not detected.

In culture supernatant, phospholipid contents averaged $1.1 \mathrm{mg} \mathrm{l}^{-1}$ and remained unchanged in the extracellular medium during growth, whereas neutral lipids more or less accumulated throughout bacterial growth. The highest yield of extracellular lipids occurred in the early stationary phase and was related to the highest production of all lipid classes, except wax esters. The early stationary phase exhibited 10, 3.5 and 2.3 fold increases respectively in extracellular mono-
Table 3. Alcaligenes sp. PHY 9 L.86. Quantitation of extracellular lipids $\left(\mathrm{mg} \mathrm{l}^{-1}\right)$ at various growth phases

\begin{tabular}{|lccccc|}
\hline Lipid & $\mathrm{T}_{1}$ & $\mathrm{~T}_{2}$ & $\mathrm{~T}_{3}$ & $\mathrm{~T}_{4}$ & $\mathrm{~T}_{5}$ \\
\hline Phospholipids & 1.29 & 1.19 & 0.90 & 1.33 & 1.26 \\
Free fatty acids & 1.69 & 1.50 & 5.75 & 1.40 & 0.53 \\
Triglycerides & 0.290 & 0.254 & 0.633 & 0.247 & 0.338 \\
Monoglycerides & 0.025 & 0.004 & 0.298 & 0.100 & 0.100 \\
Wax esters & 0.146 & 0.872 & 0.280 & 0.239 & 0.250 \\
Pigments & - & - & 0.011 & 0.026 & - \\
\hline
\end{tabular}

glycerides, free fatty acids, and triglyceride accumulation, compared with log phases. Excess of wax esters was apparent at log phase $\left(T_{1}\right)$. A production of pigmented lipids was observed at $T_{3}$ and $T_{4}$; it was related to the presence of green and yellow pigmentation in culture supernatants.

\section{Electron microscopy}

Treatment with G/RR/UA visualized the polysaccharide fibers (Fig. 4A, 3 h old cultures). At log phase fibers had developed and formed a fibrillar structure around the bacteria. Thick fibers interconnected with thinner fibrils and associated its extremity with small vesicles. In the extracellular medium, large amounts of these vesicles were trapped in a polysaccharide fiber web (Fig. 4B).

At stationary phase, most bacteria were associated with large vesicles through exopolysaccharide fibers 

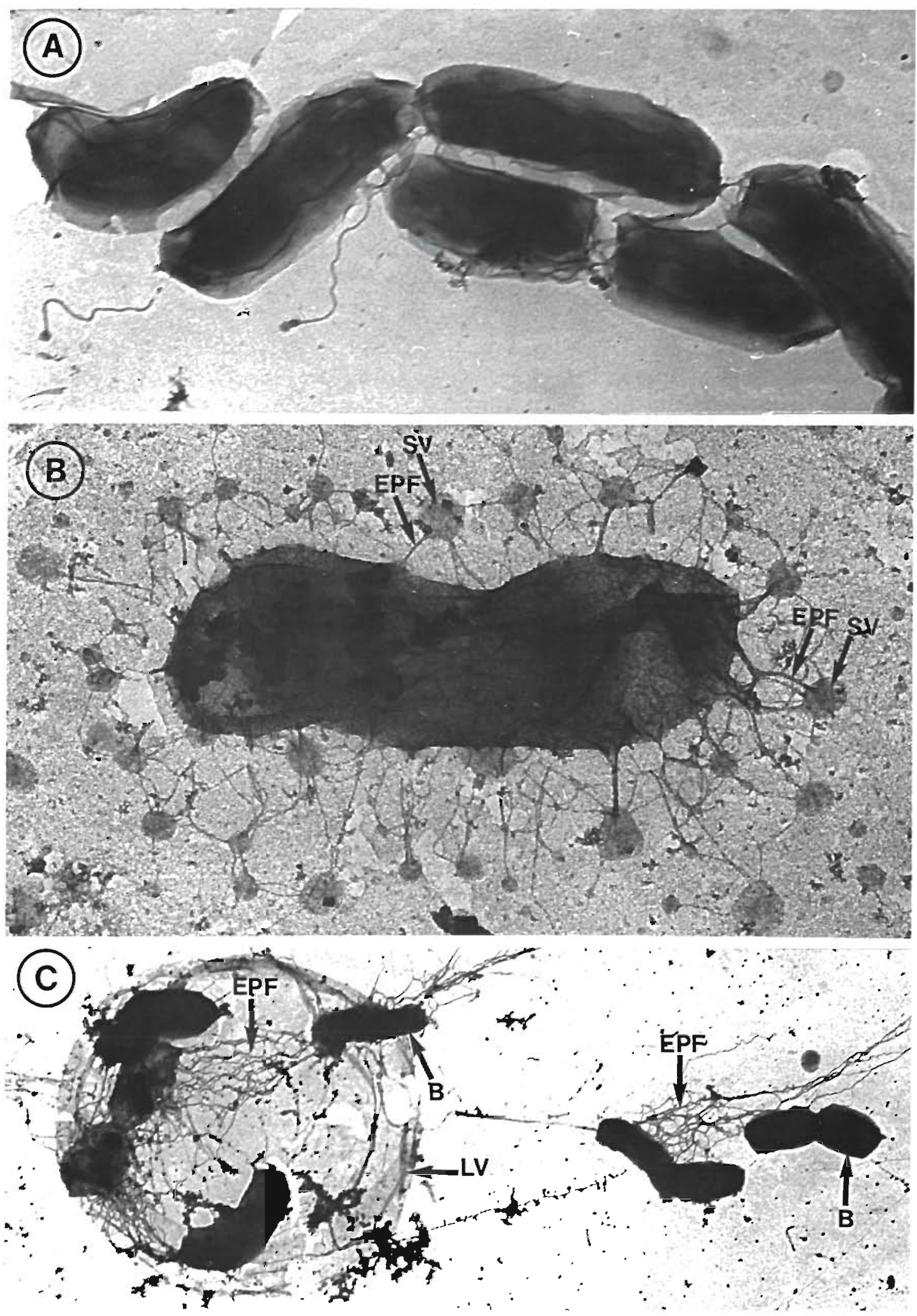

Fig 4 Alcaligenes sp. PHY 9 L.86. Electron microscopical study of tetradecane-grown cultures at different phases of growth (A) early exponential phase $(\times 32000)$, (B) log phase $(\times 70000)$, small vesicles (SV) are trapped by exopolysaccharid fibers (EPF); (C) stationary phase $(\times 16000)$, bacteria $(B)$ are associated to the surface of large vesicles (LV) by exopolysacchand fibers (EPF) 
(Fig. 4C). Sheets, that collapsed as the preparation was dried, made up the envelope of these large vesicles. The spherical conformation of these large vesicles was confirmed by a freeze-etching study (Mutaftshiev pers. comm.). We plan to investigate these structures further.

\section{Relations between extracellular compounds and morphological structures during cell growth}

Comparative studies of extracellular compounds and morphological structures, employing electron microscopy, suggest that several types of extracellular factors are involved in tetradecane assimilation during growth of Alcaligenes sp. PHY 9 L.84. (1) At log phase the presence of small vesicles linked to the cells through short exopolysacharid fibers (Fig. 4B) is related to the highest amount of lipids and tetradecane associated with cell pellets (Tables 1 \& 2). These vesicles therefore could be microemulsions resulting from emulsification process of the substrate by the lipid compunds. (2) Enhancement of 'emulsified' tetradecane (Fig. 2), as well of extracellular lipids and carbohydrates (Table 1), can be related to the dispersion of microemulsions into exopolysaccharid fibrillar material in the supernatant. At stationary phase, the presence of large vesicular structures are correlated with the maximum concentrations of extracellular carbohydrates and pigments (Fig. 4C)

\section{DISCUSSION}

The marine bacterium Alcaligenes sp. PHY 9 L.86, isolated from surface foams, appears to be well adapted to tetradecane substrate. The strain released organic compounds into the medium which provided the culture broth with emulsifying activities and foaming properties. These were due to lipids and carbohydrates. Production of such compounds has been reported for many microorganisms growing on hydrocarbon substrates (reviewed by Rosenberg 1986). Numerous authors considered the emulsification of hydrocarbons by surfaceactive agents to be an essential step in hydrocarbon biodegradation, particularly in the marine environment (Reisfeld et al. 1972, Gutnick \& Rosenberg 1977, Floodgate 1984, Bartha 1986, Mattei et al. 1986): however few data exist on detailed characteristics of extracellular lipid classes released by marine bacteria.

Using TLC/FID, we have emphasized the dynamics of lipid production in relation to the rate of hydrocarbon consumption. This analytical technique, which provides synoptic lipid class data from small samples, enables an easy and rapid sample work up procedure that we found particularly useful for studying the repartition and dynamics of lipid production throughout bacterial growth. There exists a good relationship between lipid production and emulsifying activity. Increasing lipid production is related to increasing emulsifying activity. Very low activity was estimated in the early growth phase when most tetradecane was associated with cells. Thus, direct cell contact with the substrate can be an initiating step at the beginning of growth. The emulsifying activity was enhanced during the bacterial growth and was maximal in the early stationary phase. Extracellular lipid content including fatty acids - already described as good emulsifiers (Rosenberg 1986) - attained maximum values at this stage of growth.

Using electron microscopy with specific staining for acid polysaccharides, we have revealed the precise structural organisation of carbohydrates into large exopolysaccharid fibers. The particular methodology for sample treatment used by us, involving neither centrifugation nor filtration, prevented disruption of fragile structures. Thus, we obtained more details on the structural relations between exopolysaccharids and lipids during the bacterial growth. Exopolysaccharid fibers could act as an emulsion stabilizer. Maximum exopolysaccharid production occurred in the stationary phase with fibers adhering to large vesicles of membrane-type organisation and was obviously related to foam formation. The production of an oil emulsifying agent, polysaccharide in nature, was described by Floodgate (1978) for a marine bacterium which degraded oil rapidly, and by Reisfeld et al. (1972) and Zuckerberg et al. (1979) who characterized the well known 'emulsan' as an anionic heteropolysaccharide containing fatty acid side chains, synthesized by Acinetobacter calcoaceticus RAG-1 growing in seawater.

During the growth of Alcaligenes sp. PHY 9 L.86 on tetradecane, we observed that the bacteria pass through various phases in which the physical organisation of extracellular factors tends to optimize substrate assimilation. An maximum biodegradation rate was achieved when the microbial population had provided an amount of molecules sufficient to emulsify the substrate and to stabilize the emulsion. Very high concentration of hydrocarbons (100 to $180 \mathrm{mg} \mathrm{l}^{-1}$ ) were found in the area from which Alcaligenes sp. PHY 9 L. 86 was isolated. Hence, the ability for this strain to release surface-active compounds during hydrocarbon growth can be considered an important factor in foam formation.

In open seawater, where concentrations of cells are low, an effective emulsification process is unlikely to prevail (Rosenberg 1986). In contrast, in the surface microlayer petroleum hydrocarbons accumulate to a greater extent than in the underlying water column 
(Marty \& Saliot 1976, Gearing \& Gearing 1982). An annual input of $5 \times 10^{3} \mathrm{t}$ crude oil in the form of slicks has recently been estimated by Burns \& Saliot (1986) for the Mediterranean Sea. Numerous hydrocarbon utilizers have been isolated (Crow et al. 1976), and recent studies appear to demonstrate that this biomass is highly active (Carlucci et al. 1985, William et al. 1986). Therefore, in this part of the marine environment, the emulsification process that we observed in vitro can be effective and may represent an advantage for microorganisms growing on insoluble substrates. Moreover, the input of surface-active compounds in this area could modify the physical characteristics of the ocean surface. Further investigations are needed to quantify this particular aspect of microbial activity in the sea surface microlayer.

Acknowledgements. We gratefully acknowledge the assistance of Dr Richard (Institut Pasteur, Paris) in the identification of Alcaligenes sp. This work was supported by a grant from Elf Aquitaine Society.

\section{LITERATURE CITED}

Bartha, R. (1986). Biotechnology of petroleum pollutant biodegradation. Microb. Ecol. 12: 155-172

Bligh, E. G., Dyer, W J. (1959). A rapid method of total lipid extraction and purification. Can. J. Biochem. Physiol. 37: 911-917

Buchanan, R. E., Gibbons, N. E. (ed.) (1974). Bergeys's manual of determinative bacteriology, 8th edn. Williams and Wilkins, Baltimore

Burns, K. A., Saliot, A. (1986). Petroleum hydrocarbons in the Mediterranean Sea: a mass balance. Mar Chem. 20: $141-157$

Carlucci, A. F., Craven, D. B., Henrich, S. M. (1985). Surface film microheterotrophs: amino acid metabolism and solar radiation effects on their activities. Mar. Biol. 85: 13-22

Crow, S. A., Cook, W. L., Ahearn, D. G., Bourquin, A. W. (1976). Microbial population in coastal surface slicks. In: Sharpley, J. M., Kaplan, A. M. (ed.) Proceedings of the 3rd International Biodegradation Symposium. Applied Science Publishers, London, p. 93-98

Delmas, R. P., Parrish, C. C., Ackman, R. G. (1984). Determination of lipid class concentrations in sea water by thinlayer chromatography with flame ionization detection. Analyt. Chem. 56: 1272-1277

Dubois, M., Gilles, K. A., Hamilton, J. K., Rebers, P. A., Smith, F. (1956). Colorimetric method for determination of sugars and related substances. Analyt. Chem. 28: 350-356

Floodgate, G. D. (1978). The formation of oil emulsifying agents in hydrocarbonclastic bacteria. In: Loutit, M. W.,
Miles, J. A. R. (ed.) Microbial ecology. Springer-Verlag Berlin, p. 82-85

Floodgate, G. D. (1984). The fate of petroleum in marine ecosystems. In: Atlas, R. M. (ed.) Petroleum microbiology. MacMillan, New York, p. 355-397

Gearing, P. J., Gearing, J. N. (1982). Transport of no. 2 fuel oil between water column, surface microlayer and atmosphere in controlled ecosystems. Mar environ. Res. 6: 133-143

Gutnik, D., Rosenberg, E. (1977). Oil tankers and pollution: a microbiological approach. A. Rev. Microbiol. 31: 379-396

Larsen, H. (1986). Halophilic and halotolerant microorganisms. An overview and historical perspective. FEMS (Federation of European Microbiological Societies) Microb. Rev. 39: 3-7

Lowry, O. H., Rosebrough, N. J., Farr, A. L., Randall, R. J. (1951). Protein measurement with the Folin phenol reagent. J. biol. Chem. 95: 2102-2107

Marty, J. C., Saliot, A. (1976). Hydrocarbons (normal alkanes) in the surface microlayer of sea water. Deep Sea Res. 23: 863-873

Mattei, G., Rambeloarisoa, E., Giusti, G., Rontani, J. F., Bertrand, J. C. (1986). Fermentation procedure of a crude oil in continuous culture on sea water. Appl. Microbiol. Biotechnol. 23: 302-304

Mutaftshiev, S., Vasse, J., Truchet, G. (1982). Exostructures of Rhizobium meliloti. FEMS (Federation of European Microbiological Societies) Microb. Letters 13: 171-175

Parrish, C. C., Ackman, R. G. (1983). Chromarod separations for the analysis of marine lipid classes by Jatroscan thinlayer chromatography flame ionization detection. J. Chromat. 262: 103-112

Rambeloarisoa, E., Rontani, J. F., Giusti, G., Duvjnak, Z., Bertrand, J. C. (1984). Degradation of crude oil by a mixed population of bacteria isolated from sea surface foams. Mar Biol. 83: 69-81

Reisfeld, A., Rosenberg, E., Gutnick, D. (1972). Microbial degradation of crude oil: factors affecting the dispersion in sea water by mixed and pure cultures. Appl. Microbiol. 24: 363-368

Rosenberg, E. (1986). Microbial surfactants. CRC Crit. Rev. Biotechnol. 3: 109-132

Roy, P. K., Singh, H. D., Bhagat, S. D., Baruah, J. N. (1979). Characterization of hydrocarbon emulsification and solubilization occurring during the growth of Endomycopsis lipolytica on hydrocarbon. Biotechnol. Bioeng. 21: 955-974

William, P. M., Carlucci, A. F., Henrich, S. M., van Veet, E. S., Horrigan, F. G. O., Red, F. M. H., Robertson, K. J. (1986). Chemical and microbiological studies of sea surface film in the southern Gulf of California and of the West Coast of Baja California. Mar. Chem. 19: 17-98

Zosim, Z., Gutnick, D., Rosenberg, E. (1982). Properties of hydrocarbon in water emulsions stabilized by Acinetobacter RAG-1 emulsan. Biotechnol. Bioeng. 24: 281-292

Zuckerberg, A., Diver, A., Peeri, Z., Gutnick, D. L., Rosenberg, E. (1979). Emulsifier of Arthrobacter RAG-1. chemical and physical properties. Appl. environ. Microbiol. 37: 414-420 